\title{
AQUARAD - Computer code for radionuclides dispersion calculation in river - reservoir aquatic systems
}

\author{
Al. Toma, C. Dulama and M. Pavelescu \\ Institute for Nuclear Research, Pitesti, P.O. Box 78, 0300 Arges, Romania
}

\begin{abstract}
The dispersion model used in this paper deals with steady state effluent release. It can be applied to continuous routine release of radioactive liquid effluents into a river if the transients are neglected. Based on this model, using analytical solutions, the computer code AQUARAD calculates radionuclide concentrations in river - reservoirs systems for different release conditions and configurations. AQUARAD offer acceptable results for downstream distances more than $200 \mathrm{~m}$ from the evacuation point and its structure allows improving the performances by introducing more sophisticated models. The OUTPUT INTERFACE of this code permits graphic visualization of radionuclide concentration on the river map.
\end{abstract}

\section{INTRODUCTION}

Taking into account the complexity of the radionuclides dispersion phenomena into surface aquatic environment [1] and considering the specificity of each system [2], the computer code is built in a manner that permits in the future to develop by including various geometry of the release and of the receiver system.

The computer code can be useful also for dispersion calculation in river-reservoir systems of other pollutants (chemicals, biological etc.).

\section{DISPERSION MODELS}

Generally, radionuclides dispersion in aquatic environments is described by the following equation or by a simplified one [3]:

$$
\frac{\partial \mathrm{C}}{\partial \mathrm{t}}=-\mathrm{A}+\mathrm{D}-\mathrm{R}+\mathrm{P}-\lambda \mathrm{C}
$$

Where $\mathrm{C}$ is the water concentration of a given radionuclide $\left(\mathrm{Bq} / \mathrm{m}^{3}\right)$

$A$ is the advection term

$\mathrm{D}$ is the diffusion term

$\mathrm{R}$ is the sedimentation retain rate

$\mathrm{P}$ is a term which includes the source and the radionuclide removing by various processes

$\lambda$ is the radioactive decay constant $\left(\mathrm{s}^{-1}\right)$.

The individual terms in this equation can be described as:

$$
\begin{aligned}
& \mathrm{A}=\mathrm{u} \frac{\partial C}{\partial x}+v \frac{\partial C}{\partial y}+w \frac{\partial C}{\partial z} \\
& \mathrm{D}=\frac{\partial}{\partial x}\left(K_{x} \frac{\partial C}{\partial x}\right)+\frac{\partial}{\partial y}\left(K_{y} \frac{\partial C}{\partial y}\right)+\frac{\partial}{\partial z}\left(K_{z} \frac{\partial C}{\partial z}\right) \\
& \mathrm{R}=\mathrm{K}_{\mathrm{d}} \mathrm{S} \frac{\partial C}{\partial t} \text { (for equilibrium conditions) }
\end{aligned}
$$


Where direction $\left(\mathrm{m}^{2} / \mathrm{s}\right)$;

$u, v$, and $w$ are the velocity components of water along the $x, y$ and $z$ co-ordinate axes $(\mathrm{m} / \mathrm{s})$;

$\mathrm{x}, \mathrm{y}$ and $\mathrm{z}$ co-ordinate axes;

$\mathrm{K}_{\mathrm{x}}, \mathrm{K}_{\mathrm{y}}$ and $\mathrm{K}_{\mathrm{z}}$ are the diffusion coefficients for different radionuclides in the $\mathrm{x}, \mathrm{y}$ and $z$

$\mathrm{S}$ is the suspended sediment concentration in water $\left(\mathrm{kg} / \mathrm{m}^{3}\right)$;

$\mathrm{K}_{\mathrm{d}}$ is the equilibrium distribution coefficient between sediment and water $\left(\mathrm{m}^{3} / \mathrm{kg}\right)$.

By vertical averaging of the usual equation for convective diffusion one can obtain in equilibrium conditions the following equation for a given radionuclide:

$$
\overline{\mathrm{u}}(\mathrm{y}) \mathrm{d}(\mathrm{y}) \frac{\partial \overline{\mathrm{C}}}{\partial \mathrm{x}}=\frac{\partial}{\partial \mathrm{y}}\left[\overline{\mathrm{K}}_{\mathrm{y}}(\mathrm{y}) \mathrm{d}(\mathrm{y}) \frac{\partial \overline{\mathrm{C}}}{\partial \mathrm{y}}\right]-\lambda \mathrm{d} \overline{\mathrm{C}}
$$

Where $\bar{C}$ is the water concentration of a given radionuclide within the river $\left(\mathrm{Bq} / \mathrm{m}^{3}\right)$

$\mathrm{d}(\mathrm{y})$ is the river bed depth $(\mathrm{m})$

$\bar{K}_{y}(y)$ is the lateral turbulent diffusion coefficient (vertically averaged) $\left(\mathrm{m}^{2} / \mathrm{s}\right)$

$\bar{u}(y)$ is the vertically averaged velocity $(\mathrm{m} / \mathrm{s})$

$\lambda$ is the radioactive decay constant $\left(\mathrm{s}^{-1}\right)$.

For strongly stratified rivers $d(y)$ might be considered as depth of thermal inversion level since the enhanced thermal gradient inhibits the mixing in the vicinity of the riverbed.

Generally, for the rivers, the longitudinal advection is much more important than the longitudinal diffusion.

In the case of a linear source an approximate solution can be obtained analytically:

$$
\bar{C}(x, q)=\frac{W}{Q}\left[1+2 \sum_{n=1}^{\infty} e^{-\frac{n^{2} \pi^{2} D x}{Q^{2}}} \cos \frac{n \pi q_{s}}{Q} \cos \frac{n \pi q}{Q}\right] e^{-\frac{\lambda x}{\bar{u}}}
$$

Where $\mathrm{q}$ is the cumulative flow between $\mathrm{y}_{0}=0$ and $\mathrm{y}, \mathrm{q}=\int_{0}^{0}(u d) d y\left(\mathrm{~m}^{3} / \mathrm{s}\right)$;

$\mathrm{Q}$ is the total river flow $\left(\mathrm{m}^{3} / \mathrm{s}\right)$;

$\bar{u}$ is the average value of $u$ for the cross section of the stream $(\mathrm{m} / \mathrm{s})$.

One consider the linear source thickness $\mathrm{y}_{\mathrm{s}}$ which corresponds to a cumulative flow $\mathrm{q}_{\mathrm{s}}$

$\mathrm{D}$ is the average of $\mathrm{K}_{\mathrm{y}} \mathrm{ud}^{2}$ weighted with the flow, $\mathrm{D}=\frac{1}{Q} \int_{0}^{Q} \bar{K}_{y} u d^{2} d q\left(\mathrm{~m}^{5} / \mathrm{s}^{2}\right)$.

For a plane source of area $W$, sited between $y_{s 1}$ and $y_{s 2}$ with the corresponding flows $q_{s 1}$ and $q_{s 2}$ the radionuclide concentration in a given point shall be:

$$
\begin{gathered}
\overline{\mathrm{C}}(\mathrm{x}, \mathrm{q})=\frac{\mathrm{W}}{\mathrm{Q}}\left[1+2 \sum_{\mathrm{n}=1}^{\infty} \mathrm{e}^{-\frac{\mathrm{n}^{2} \pi^{2} \mathrm{Dx}}{\mathrm{Q}^{2}}} \frac{\sin \mathrm{n} \delta}{\mathrm{n} \delta} \cos \frac{\mathrm{n} \pi}{2}\left(\frac{\mathrm{q}_{\mathrm{s} 1}+\mathrm{q}_{\mathrm{s} 2}}{\mathrm{Q}}\right) \cos \frac{\mathrm{n} \pi \mathrm{q}}{\mathrm{Q}}\right] \\
\text { Where } \delta=\frac{\pi}{2}\left(\frac{\mathrm{q}_{\mathrm{s} 2}-\mathrm{q}_{\mathrm{s} 1}}{\mathrm{Q}}\right)
\end{gathered}
$$

The equilibrium flow model is used for the rivers having a predominant unidimensional flow. The river can be stratified or with total mixing. This model does not consider the sedimentation effects. If the river has downstream an important tributary, the dilution is calculated until the junction point and then the procedure is restarted with the new value of the river flow.

In order to use this model the following are to be known:

a) River bed geometry

b) Velocity distribution within the cross section of the stream such to determine $\bar{u}$ 
c) Dilution coefficient in the representative cross sections such to determine $\mathrm{K}_{\mathrm{y}} \mathrm{ud}^{2}$.

It is preferable to calculate $\bar{u}$ by using the cross section distribution of velocities obtained by measurement. However $\bar{u}$ can be assessed from the river flows measured in the hydrological measuring stations. Since the measured velocities cover a broad range of values for each cross section, it is usual to estimate the $u(y)$ distribution over the cross section for each type of profile and to apply the equations to the equilibrium flow.

If the release is done in the vicinity of the shore, the concentration along this shore decreases with $\mathrm{x}^{-1 / 2}$ because of the bidimensional mixing.

The way the complete mixing length is to be assessed is immediate. To be mentioned that the complete mixing length for a near shore release is four times greater than those for a mid stream release.

\section{CODE PRESENTATION}

On this model basis a computer program, AQUARAD, was written in Visual Basic language. Analytical solutions were used to solve the model integrals. Thus, by avoiding the numeric calculation of integrals the computing time was drastic reduced without significant changes in the precision of results.

By analysing the convergence of the series from the solution one established that the program gives acceptable results for distances greater than $200 \mathrm{~m}$ from the release point.

Two interfaces were designed, one for parameter input and the other for results output. The program is versatile, allowing the user to choose the riverbed profile, water stream mean velocity profile, release geometry and other parameters of the model.

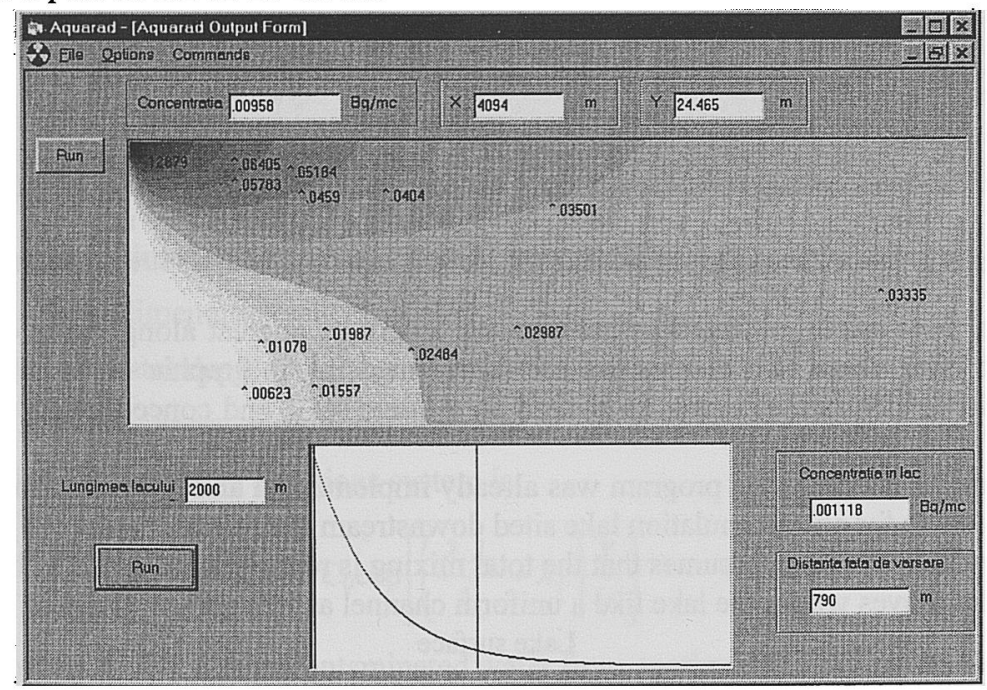

Figure 1: The output interface window of the program

In case one decide to calculate the radionuclide concentration within a given grid, the program can graphically output the results as a concentration map downstream for a length required by the user. Using this feature and performing successive runs can obtain a valuable image over the dispersion phenomena obtained as to be able to improve the release geometry for a real situation. In this manner one can perform an optimisation in the design stage for an emitter - receiver system. release.

The Figure 2 shows the concentration map for a certain radionuclide in the case of a near shore

One can observe the effluent attaching to shore phenomenon, which leads to enhanced values of radionuclide concentration lasting for relatively long distances from the releasing point. This is not observed in the case of a mid stream release as can be seen in the Figure 3. 


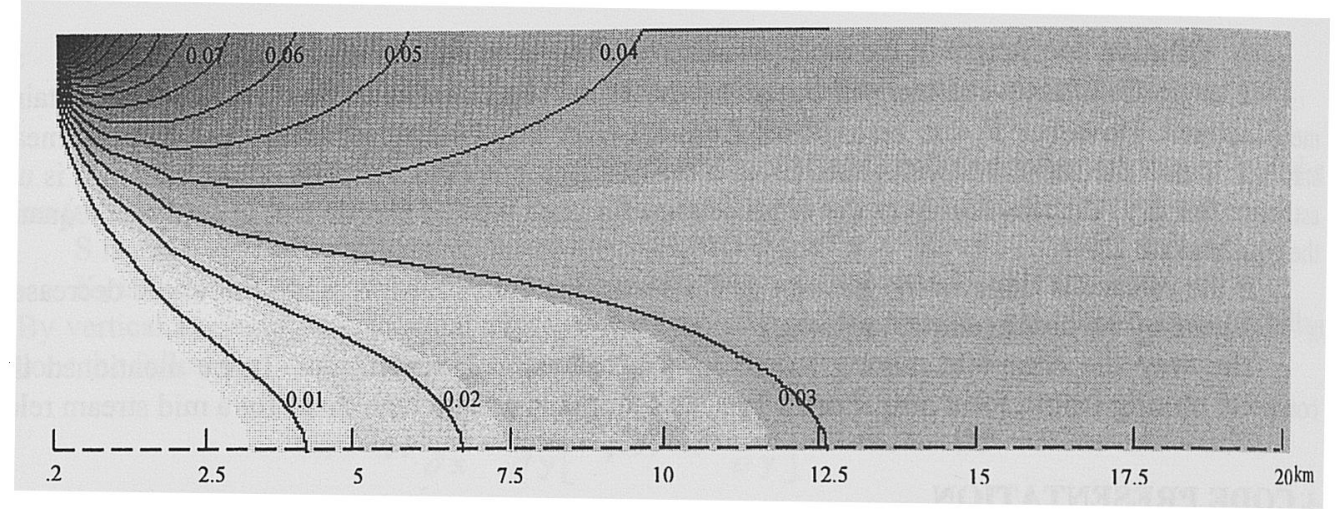

Figure 2: Concentration map for a certain radionuclide in the case of a near shore release

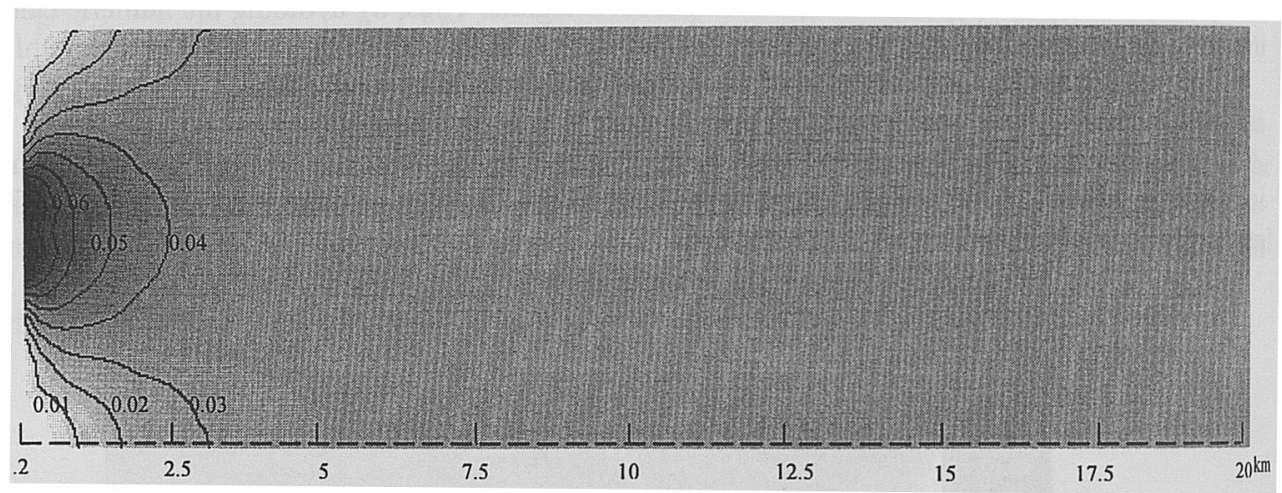

Figure 3: Concentration map for a certain radionuclide in the case of a mid stream release

Since there are big differences between the length of interest along the river and the width of the river, these two dimensions are represented in the graphic output at different scales. The isoconcentration curves are plotted on a linear scale and concentration values are given in $\mathrm{Bq} / \mathrm{m}^{3}$.

An improvement of the program was already implemented and it consists in attaching dispersion module for an accumulation lake sited downstream the release point $[4,5]$.

The model, which was used, assumes that the total mixing is reached upstream the drain of the river water moves within the lake like a uniform channel as it is shown in figure below.

Lake surface

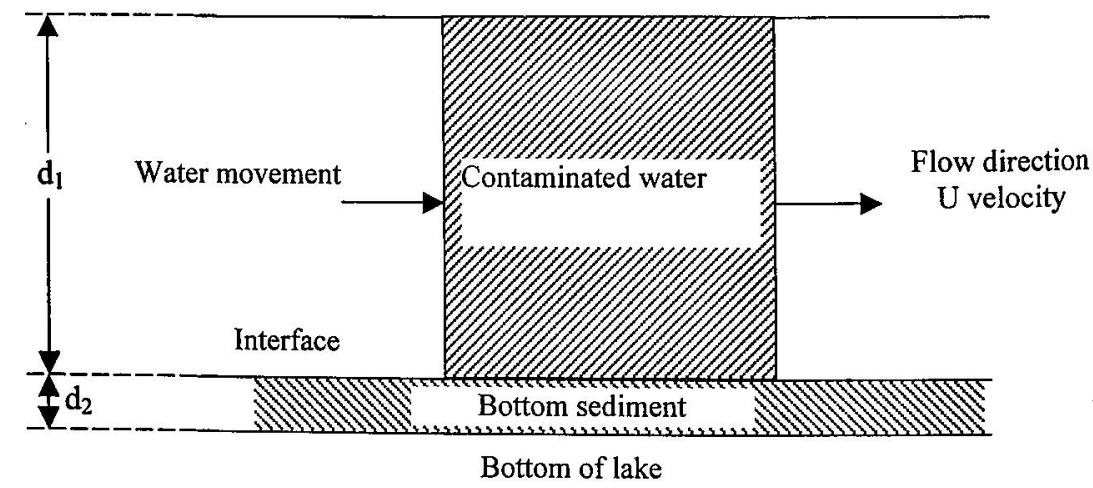

Figure 4: Diagram of the lake dispersion model 
The equations, which are used, are:

$$
\begin{aligned}
& \mathrm{U} \frac{d C}{d x}=\lambda_{1} \mathrm{C}_{\mathrm{b}}-\lambda_{2} \mathrm{C} \\
& \mathrm{C}_{\mathrm{b}}=\frac{\lambda_{3}}{\lambda_{4}} \mathrm{C}
\end{aligned}
$$

Where $\quad \lambda_{1}=\frac{K_{f}}{d \cdot K_{d}}$

$$
\lambda_{2}=\lambda+\frac{\varepsilon \cdot v K_{d}}{d}+\frac{K_{f}}{d_{1}}
$$

$\lambda_{3}=\frac{\varepsilon \cdot v K_{d}}{d_{2}}+\frac{K_{f}}{d_{2}}$

$\lambda_{4}=\left(\lambda+\frac{\varepsilon \cdot v}{d_{2}}+\frac{K_{f}}{d_{2}}\right) \cdot \frac{1}{K_{d}}$

Where $U$ is the average velocity of the water within the channel $(\mathrm{m} / \mathrm{s})$,

$\mathrm{C}$ is the radionuclide concentration in water $\left(\mathrm{Bq} / \mathrm{m}^{3}\right)$,

$\mathrm{C}_{\mathrm{b}}$ is the radionuclide concentration in sediment $(\mathrm{Bq} / \mathrm{kg})$,

$\mathrm{K}_{\mathrm{f}}$ is the direct transfer coefficient between the water and the sediment layer $(\mathrm{m} / \mathrm{s})$,

$\mathrm{d}$ is the depth of the lake equal $d_{1}+d_{2}=$ const. (m)

$\mathrm{K}_{\mathrm{d}}$ is the distribution coefficient $\left(\mathrm{m}^{3} / \mathrm{kg}\right)$,

$\varepsilon$ is the sediment effectiveness factor (fitting coefficient),

$\mathrm{v}$ is the sedimentation velocity $(\mathrm{m} / \mathrm{s})$,

$\mathrm{d}_{1}$ is the water depth (m),

$d_{2}$ is the thickness of sediment layer $(m)$.

The solution for the above equations system is:

$$
\mathrm{C}(\mathrm{x})=\mathrm{C}_{0} \exp \left[\left(\frac{\lambda_{1} \lambda_{3}}{\lambda_{4}}-\lambda_{2}\right) \frac{X}{U}\right]
$$

In case the lake is fed with uncontaminated water from another river having the flow $Q$ and the radionuclide carrier river flow is $q$ then the concentration in the junction point will be:

$$
\mathrm{C}(\mathrm{x})=\mathrm{C}_{0} \frac{q}{Q+q} \exp \left[\left(\frac{\lambda_{1} \lambda_{3}}{\lambda_{4}}-\lambda_{2}\right) \frac{X}{U}\right]
$$

The model will be completed for dose calculation in order to establish derived release limits for radioactive liquid effluents discharged into a river - reservoir system. The computer code is realized using object oriented programming techniques, which ensure accessibility and flexibility. The installation kit gives portability to the program with minimum required hardware and software support systems.

Certain experiments using radionuclides discharged from the nuclear facilities of the Institute for Nuclear Research and Nuclear Fuel Factory into the Doamnei River - Arges Reservoir system are running to validate the program and to improve the models used. 


\section{References}

[1] D. Cioc, Hidraulic $\diamond$, Ed. Didactic $\diamond \star$ i Pedagogic $\diamond$, Bucure $\star$ ti, 1975

[2] P. Roman, Introducere în Fizica Poluării Fluidelor, Editura Ştiințifică şi Enciclopedică, Bucureşti, 1980

[3] Vandecasteele C. M., "Transfer of Radionuclides in Aquatic Ecosystems», IUR Summer School, Neptun, Romania, 1997

[4] Al. Toma, M. Pavelescu, «Radionuclides Behaviour in the Solid Phase into a River - Reservoir System», IRPA Regional Congress on Radiation Protection in Central Europe, August 22 - 27, 1999, Budapest, Hungary, Proceedings (on CD, ISBN 963805188 4), Publisher: Health Physics Section Roland Eötvös Physical Society

[5] Al. Toma, M. Pavelescu, Critical Pathways for Radionuclides Transfer in Aquatic System, Proc. Suppl. BPL, 5 (1997). 